\title{
Bem-viver-interespécies: reflexões iniciais
}

\author{
Good-living-interspecies: initial reflections \\ Buen-vivir-interespecies: reflexiones iniciales \\ LUCIANA CRISTINA GodoY ${ }^{1}$ \\ Universidade Federal de São Carlos, UFSCAR, SÃo CARLos-SP, BraSIL
}

\begin{abstract}
RESUMO
Este ensaio propõe-se a apresentar o Bem-Viver-Interespécies, como anúncio de uma ética de solidariedade, empatia e alteridade entre Seres-Humanos e Seres-Animais. Para tal, concebemos a possibilidade da interconexão conceitual entre Bem-Viver e os Estudos Críticos Animais. Nosso objetivo é destacar os principais pontos que levam à defesa de outros modelos descoloniais da forma básica de classificação social, inclusive da espécie, no eixo de poder na relação interespécies (humanos e animais). Reconhecemos, por certo, a existência da pluralidade conceitual e política no campo de ativismo relacionado à causa animal. Deste modo, nosso entendimento atual deve ser interpretado como uma conjectura, e não propriamente a uma proposição teóricoconceitual, uma vez que ainda estamos nos estágios iniciais de nossa pesquisa.
\end{abstract}

Palavras-chave: Bem-Viver. Estudos Críticos Animais. Estudos Descoloniais.

\begin{abstract}
This essay strives to introduce the Good-Living-Interspecies, as an announcement of an ethics of solidarity, empathy and otherness between Human-Beings and Animal-Beings. With this subject, we conceive the possibility of the conceptual interconnection between Good-Living and Critical Animal Studies. Our goal is to highlight salient points that lead to the defense of other descolonial models of the basic form of social classification, including species on the axis of power in the interspecies relationship (human and animal). We certainly recognize the existence of the conceptual and political plurality in the field of animal activism. Thus, our current understanding must be construed as a conjecture rather than a proposition, given we are still in the initial stages of our research.
\end{abstract}

Keywords: Good-Living. Animal Critical Studies. Descolonial Studies.

\section{RESUMEN}

Este ensayo se propone presentar el Buen-Vivir-Interespecies, como anuncio de una ética de solidaridad, empatía y alteridad entre Seres-Humanos y Seres-Animales. Para ello, concebimos la posibilidad de la interconexión conceptual entre Buen-Vivir y los Estudios Críticos Animales. Nuestro objetivo es destacar los principales puntos que llevan a la defensa de otros modelos descoloniales de la forma básica de clasificación social, incluso de la especie, en el eje de poder en la relación interespecies (humanos y animales). Ciertamente reconocemos la existencia de la pluralidad conceptual y política en el campo de activismo relacionado con la causa animal. De este modo, nuestro entendimiento actual debe ser interpretado como una conjetura, y no propiamente a una proposición teórico-conceptual, puesto que aún estamos en las etapas iniciales de nuestra investigación.

Palabras clave: Buen-Vivir. Estudios Críticos Animales. Estudios Descoloniales.

\footnotetext{
1 Doutoranda em Educação do Programa de Pós-Graduação em Educação da UFSCar. E-mail: lucianna.crgodoy@gmail.com
} 


\section{INTRODUÇÃOO}

Entre as diversas inquietações ${ }^{2}$ éticas e epistemológicas que despertam nossos interesses e intenções, deparamos hoje com algumas que nos chamam atenção por envolver importância vital para a vida humana: a relação dos Seres-Humanos com o demais Seres-Vivos. Desde a publicação do livro Libertação Animal, Peter Singer, em $1975^{3}$, tem-se intensificado, paulatinamente, no contexto acadêmico, questionamentos referentes às relações interespécies -entre Seres-Humanos e Seres-Animais-, originando, inicialmente no Reino Unido e Estados Unidos, algumas áreas como Animal Studies (Estudos Animais), posteriormente, Critical Animal Studies (Estudos Críticos Animais) e, mais recentemente, Animal Turn (Virada Animalista) no campo da Antropologia.

Na América Latina em geral, bem como no Brasil, a discussão acadêmica acerca das mudanças paradigmáticas que a temática demanda ainda é recente, conforme afirmam Castellano e Sorrentino (2015). Os estudos em torno da opressão entre SeresHumanos e Seres-Animais começam a ganhar espaço a partir do século XXI, com a tradução de algumas obras de referência, circulação do tema via internet, publicações de trabalhos acadêmicos e, sobretudo, o crescimento do ativismo relacionado à causa animal $^{4}$, que em muito tem contribuído para ampliação do tema.

No contexto brasileiro, a causa animal é um tipo de ativismo complexo que tem atraído atenção de pesquisadores/as (BRÜGGER, 1999; FELIPE, 2003; NACONECY, 2014). Nesse contexto, como aponta o filósofo e ativista brasileiro Naconecy (2014), os movimentos organizam-se em um longo fluxo envolvendo um largo espectro de pessoas e grupos, que elegem, a partir de réguas graduadas das mais diversas escalas de valor e espécie, alguns Seres-Animais para serem alvos de suas atuações.

No campo das organizações e movimentos sociais, há no Brasil, especialmente nas últimas quatro décadas, um número significativo de sociedades, organizações e movimentos que se preocupam com a causa animal, protegendo e/ou defendendo o bem-estar e/ou direitos dos Seres-Animais. Todavia, de acordo com Ostos (2017), o primeiro registro no país é da União Internacional Protetora dos Animais (UIPA), criada na cidade de São Paulo, em 1895, a qual está em atividade até atualidade. Essas pessoas, grupos e/ou comunidades ao se relacionarem constituem práticas sociais que visam subverter uma dada realidade antropocêntrica, embora haja tanto proximidades quanto diferenças entre elas dentro da própria teia de significações que tecem a causa animal; há uma integração na circulação de valores e saberes na prática social do ativismo pela causa animal.

Cabe destacar, também, a polarização conceitual, apontada por Naconecy (2014), que vem permeando os movimentos sociais da causa animal neste cenário diverso. Segundo o autor, as vertentes se organizam basicamente nos movimentos de proteção e defesa animal, apresentados como bem-estaristas, e no movimento vegano, autodeclarado como abolicionista e com forte atuação contra exploração animal de toda e qualquer forma, ao considerar os aspectos de: alimentação, entretenimento, testes científicos, vestuário, entre outros.

\footnotetext{
${ }^{2}$ As inquietações deste ensaio fazem parte de tese de doutorado em desenvolvimento orientada pela Profa. Dra. Maria Waldenez de Oliveira, na Linha de Pesquisa "Práticas Sociais e Processos Educativos" do Programa de Pós-Graduação em Educação da Universidade Federal de São Carlos (PPGE/UFSCar). A citada tese em desenvolvimento versa acerca dos processos educativos emergentes da prática social do ativismo pela causa animal, desde aqueles/as que se reconhecem como ativistas.

${ }^{3}$ Primeira edição no Brasil: Singer (2010).

${ }^{4}$ Neste ensaio, utilizaremos a expressão causa animal para fazer referência à literatura que traz como objeto de estudo o Ser-Animal: Animal Liberation (SINGER, 2010), Animal Studies (HARAWAY, 2008; MACIEL, 2011) e Critical Animal Studies (BEST, 2009).
} 
Este ensaio propositivo localiza-se no campo dos Estudos Críticos Animais (BEST, 2009; ÁVILA-GAITÁN, 2017), procurando estabelecer aproximações com Estudos Descoloniais (DUSSEL, 1977; FREIRE, 2011; OLIVEIRA et al., 2014; SANTOS, 2010; QUIJANO, 2013; MALDONADO-TORRES, 2010; ACOSTA, 2016). Entendemos que se trata de campos de estudos com potencial político-epistêmico de compreensão de Seres-Humanos - Seres-Animais como seres integrados e interdependentes, que podem romper com a persistente colonialidade do Ser-Humano para com outros Seres-Vivos não humanos (particularmente neste ensaio: "SeresAnimais"), que os colocam na exterioridade, ou seja, como Não Ser, dada sua condição de recurso (material-capital) dentro da lógica hegemônica do modelo colonial capitalista. Defenderemos outros modelos descoloniais da forma básica de classificação social, inclusive da espécie, neste caso, no eixo de poder na relação Seres-Humanos Seres-Animais. É neste sentido que se fundamenta o objetivo deste ensaio, o qual pretende apresentar nossa compreensão do Bem-Viver-Interespécies, como princípio ético e de vida.

\section{Alteridade Animal}

Lévinas (2005), acerca da alteridade, nos ensina que não basta saber da existência de outrem, é preciso ter este como critério, ou seja, firmar postura ética pelo respeito e reconhecimento da alteridade, colocando-se no lugar de outrem. O citado autor refere-se ao contexto europeu em que viveu e mesmo foi vítima, em que parte dos humanos vinculados ao nazismo promoveu o holocausto judeu.

No contexto de América Latina, tomamos as discussões acerca do outrem de Dussel (1997) e Araújo-Olivera (2014), que tratam da totalidade colonialista de parte dos europeus sobre a exterioridade de povos indígenas, afro-brasileiros e africanos, tendo-os escravizado, inferiorizado e invisibilizado. Conforme Enrique Dussel (1997), Anibal Quijano (2013) e Boaventura de Sousa Santos (2010), a perspectiva do homem branco europeu do período da colonização, se mantem até os dias atuais no contexto da colonialidade, pautando-se, sobretudo, na discriminação de Seres-Humanos (por exemplo: grupos étnico-raciais negros e indígenas, tratados na esfera do Não Ser) outros Seres-Humanos.

Prossegue Santos (2010) que o pensamento ocidental cartesiano elegeu monoculturas, produzindo não-existências e constituindo-se enquanto pensamento abissal, dividindo os conhecimentos em deste lado da linha (existentes e válidos) e do outro lado da linha (não-existentes e não válidos). Para este autor existem monoculturas ou modos de produção de não-existências, das quais chamamos a atenção neste estudo, da monocultura da naturalização das diferenças, a qual possui lógica de classificação social, racial, sexual que visa naturalizar hierarquias. Nesta lógica, "a não-existência é produzida sob a forma de inferioridade insuperável porque natural. Quem é inferior, porque é insuperavelmente inferior, não pode ser uma alternativa credível a quem é superior" (p.103). Nessa monocultura, entendemos, é produzida a não-existência da maior parcela de Seres-Humanos (indígenas, negros/as, pessoas empobrecidas) e a totalidade de Seres-Animais-oprimidos, torturados e escravizados.

No tocante a escravização de Seres-Animais, estes têm sido, sobretudo, tratados na esfera da domesticação e docilização, disfarçando a escravização, particularmente para Seres-Humanos que fariam oposição a ela, se assim fosse tratada. Destacamos com relação a esta esfera, os trabalhos de Forte (2017) e Videla (2017) que contribuem ao debate sobre a opressão no domínio da linguagem e fomentam um tipo de tratamento 
linguístico mais igualitário aos Seres-Animais. Forte (2017) argumenta que a querela pela imposição de signos e interpretações animalescas na atualidade, assemelha-se à disputa dos séculos XVIII e XIX sobre a escravização, do ponto linguístico. De acordo com o autor (2017, p. 107) "[...] el discurso especista no es diferente del discurso racista, misógino o antisemita. Todos son parte de la lógica discriminadora del discurso occidental de posguerra". O corpus midiático analisado no estudo do autor (FORTE, 2017) - no quadro da análise crítica do discurso - indica que as representações de espécies não apenas coisificam como também, na medida em que são empurrados à margem da inferiorização e invisibilização, do Não Ser, não são objetos de discussão e, de tal modo, são apagados do discurso.

Neste mesmo sentido, Videla (2017) ao discutir a maneira dupla em que os animais são considerados e tratados, discorrendo sobre a diferenciação semântica dos termos bicho de estimação (mascota/pet) e animal de companhia, problematiza a domesticação do primeiro termo, sobressaindo a assimetria e hierarquização desta acepção, com a ideia de animal de companhia, alocando esta como uma expressão que denota uma relação mais igualitária interespécies. Na discussão teórica apresentada pelo autor, observamos que o status de animal de companhia tem contribuído para o avanço do reconhecimento da totalidade destes animais (ainda que restrito aos domésticos, como cães e gatos) enquanto seres sencientes, embora de modo paradoxal, pois embora considerados "companheiros" permanecem produtos/propriedades na lógica mercantil capitalista-consumista.

Com estas afirmações os autores nos chamam atenção ao fato de que a linguagem é apenas um dos diversos domínios sociais e culturais que produzem negações aos Seres-Animais e, por conseguinte, produção de sua não-existência. Dentre outros, elucidamos que a negação e escravização destes seres, têm-se dado igualmente em outras situações, entre as quais listamos:

\section{- Domesticação de Seres-Animais para:}

a) abate e consumo (ex.: vaca, galinha, porco, salmão, entre outros); destacadamente humano, mas também para Seres-Animais (na forma de ração, por exemplo);

b) mercadorias de luxo e ornamento, vivos e tratados como animais de estimação e/ou mascotes e/ou possessão, algumas raças inclusive criadas em laboratório com variadas características que podem agradar mais aos possíveis compradores/donos. Ademais, Seres-Animais são comumente separados de outros de sua própria espécie, impedindo a sociabilidade deles com seus semelhantes (ex.: cachorro, gato, pássaros, peixes denominados ornamentais, entre outros). Boa parte possivelmente não percebendo sua ação especista (racista) pela própria ideologia construída em torno do consumismo também de Seres-Animais e produtos relacionados a estes;

c) trabalho (ex.: cavalos para equoterapia, mulas para transporte de pessoas e cargas, pombos correios, cães empregados como guias para deficientes visuais totais, como também em ações policiais, militares, de caça, de repressão e de tortura, entre outros);

d) cobaias (ex.: macacos, camundongos, sapos, entre outros usados em laboratórios para testes de drogas medicamentosas, maquiagens, protetores solares e mesmo produção de ração para Seres-Animais domesticados ou encarcerados em zoológicos).

\section{- Caça de Seres-Animais para:}


a) abate e consumo especialmente da carne (ex.: javali, jacaré, paca, tatu, entre outros) destacadamente humano, mas também gerando treino e prêmio de SeresAnimais (cachorros, por exemplo, pelo desempenho na caça de outros Seres-Animais);

b) mercadorias de luxo e ornamento, mortos (ex.: onças que originam peças empalhadas, cabeças de alce que são expostas como troféus fixados em paredes, marfim de elefantes para confecção de joias e objetos preciosos, chifre de rinoceronte para produção de afrodisíacos, entre outros);

c) diversão (caça pelo simples prazer e/ou entretenimento de parte dos humanos pelo abater, matar animais pelo desafio da caçada, do esporte);

d) exposição (zoológicos, onde animais são aprisionados, fora de seu habitat natural e modo de vida, por vezes com justificativa de parte dos humanos de estudo e proteção animal e/ou da espécie).

Conforme afirma Haraway (2008), há também a possibilidade, no que diz respeito à domesticação, de que se Seres-Humanos domesticaram cães, gatos, cavalos, entre outros Seres-Animais; estes também, por sua vez, domesticaram os Seres-Humanos, podendo representar construção de vínculos voluntários, cooperativos, solidários e empáticos entre espécies, e não necessariamente ação exclusiva de uma espécie (SeresHumanos - sujeitos) sobre outra (Seres-Animais - objetos). Para a autora, não somente Seres-Humanos são produtores e portadores de cultura, mas também os Seres-Animais.

Huizinga (2000) e Caillois (2017) em seus estudos sobre o jogo, entendido como elemento da cultura, vão afirmar que os animais também jogam. Escreveu Huizinga (2000):

\footnotetext{
Os animais brincam tal como os homens. Bastará que observemos os cachorrinhos para constatar que, em suas alegres evoluções, encontram-se presentes todos os elementos essenciais do jogo humano. Convidam-se uns aos outros para brincar mediante um certo ritual de atitudes e gestos. Respeitam a regra que os proíbe morderem, ou pelo menos com violência, a orelha do próximo. Fingem ficar zangados e, o que é mais importante, eles, em tudo isto, experimentam evidentemente imenso prazer e divertimento [...]. Se os animais são capazes de brincar, é porque são alguma coisa mais do que simples seres mecânicos (p. 3-6).
}

Caillois (2017), por sua vez detalha ao contrário do que poderia aparecer - que os Seres-Animais não entendem regras ou limites e seguiriam em combates brutais - são patentes os jogos de equilíbrio e perseguição de gatos, cães, focas, bovídeos, cavalos e ursos que medem forças entre si "cujo divertimento é derrubarem-se uns aos outros, evitando, no entanto, se machucarem" (p. 51). Prossegue comentando também jogos de luta e exemplifica com jogos de pavões, não domesticados, em que estes escolhem como campo de enfrentamento local úmido, coberto de relva rasa e com diâmetro de aproximadamente dois metros em que estes: "Arremessam-se um contra o outro, de bico em riste e atacam. Nunca há perseguição ou luta fora do espaço delimitado para o torneio. [...] uma vez que ficou claro que a finalidade dos antagonistas não é de causar um estrago sério no seu adversário, mas sim o de demonstrar a sua própria superioridade" (p. 52 - itálico do autor).

Ainda sobre elemento da cultura, De Wall (2010) destaca o protesto. Enfatiza que devemos rever nossos pressupostos sobre a natureza humana recordando-nos que nossa capacidade de atuar em grupo e estabelecer redes é uma habilidade de sobrevivência decisiva. Sobrevivemos cooperando e compartilhando recursos, uma vez que não seríamos (enquanto espécie humana, dentre as outras) "o que somos hoje se nossos ancestrais tivessem vivido isolados uns dos outros" (p. 19). Continua apontando que a 
competição, mesmo sendo inerente tanto aos Seres-Humanos, quanto a alguns SeresAnimais, não é o fator o que sobressai à natureza destes seres (animal e humana). Seguindo estas considerações, sobre o manifesto enquanto ação coletiva De Wall (2010, p. 16) menciona que:

Pesquisas novas e estimulantes sobre as origens do altruísmo e da justiça têm sido realizadas tanto em seres humanos como em outros animais. Por exemplo, se dois macacos receberem recompensas muito diferentes pela mesma tarefa, aquele que ficar em desvantagem simplesmente se recusará a executá-la. Também na nossa espécie os indivíduos se recusam a aceitar um salário que eles considerem injusto. Uma vez que todo pagamento, seja ele qual for, é maior do que nenhum pagamento, isso significa que os macacos, assim como as pessoas, não seguem o princípio do lucro ao pé da letra. $\mathrm{O}$ protesto dos macacos contra a desigualdade comprova tanto a importância dos incentivos quanto a aversão natural à injustiça por parte desses animais.

Alguns/as autores/as (VARELA; THOMPSON; ROSCH, 1997; PODBERSCEK; PAUL; SERPELL, 2005; HARAWAY, 2008; WILSON, 2008; DE WAAL, 2010; KIRKSEY; HELMREICH, 2010; OGDEN; HALL; TANITA, 2013; SÜSSEKIND, 2014; MATURANA; DÁVILA, 2015; VANDER-VELDEN, 2018), entendem que Seres-Animais têm uma história própria, são também atores, possuem cultura própria, e não são apenas coadjuvantes ou espectadores de ações realizadas exclusivamente por Seres-Humanos, observando que a história de Seres-Humanos e Seres-Animais têm se entrelaçado, por vezes em cooperação, em outras em antagonismo, mas, sobretudo, enquanto Seres integrados e interdependentes que com respectivas diversidades precisam uns dos outros para existência, co-existência e co-evolução na Terra.

Neste sentido, Varela, Thompson e Rosch (1997) demonstram em seus estudos diferentes formas do que denominam acoplamento, tecendo crítica a perspectiva evolucionista do neodarwinismo, enquanto processo de sobrevivência dos mais fortes, articulando uma visão alternativa da evolução como deriva natural ${ }^{5}$. Tal visão da evolução, proposta pelos autores, sustenta que histórias singulares de conexões, em que se processa o princípio que chamam de "em-ação", que estas "em-atuam", ou seja, coatuam, co-intencionadas no viver a vida. Prosseguem afirmando que Seres-Vivos e meio ambiente não podem se separar, se co-determinam. Exemplificam o princípio "emação" de co-intencionalidade a partir das abelhas e das flores: há diversos espectros de cor (refletância na superfície da Terra) que se especificam em acordo com a atividade perceptiva guiada de Seres-Animais, pois sendo as abelhas tricromáticas e estando a sensibilidade espectral delas para o ultravioleta perguntam: Quem nasceu primeiro o ovo (a refletância ultravioleta da Terra) ou a galinha (a imagem ou visão sensível ao ultravioleta)? Os autores respondem que as cores das flores co-evoluíram com a visão tricromática das abelhas, sensíveis ao ultravioleta, pois as flores atraem polinizadores para poderem se reproduzir e se manter vivas e, deste modo, precisam ser atrativas as abelhas, distinguindo-se em suas cores de outros seres vivos. Ao mesmo tempo as abelhas recolhem alimentos das flores para igualmente se manterem vivas, necessitando reconhecer as flores das quais precisam à distância. Varela, Thompson e Rosch (1997) afirmam ainda que as regularidades ambientais não são pré-dadas, mas são características da "em-atuação" que emerge através de uma história de acoplamento para a co-evolução. Ou seja, os Seres-Vivos têm construído em cooperação,

\footnotetext{
${ }^{5}$ De acordo com Varela, Thompson e Rosch (1997, p. 219) “[...] la evolución como deriva natural es el equivalente biológico de la cognición como acción corporizada. La evolución como deriva natural brinda pues un contexto teórico más amplio para el estudio de la cognición como fenómeno biológico”.
} 
solidariedade e empatia - embora, conforme assinalado anteriormente, também em competição (DE WALL, 2010) - a condição para uma continua evolução e reconstrução da natureza.

Em acordo, De Wall (2010), também tece crítica ao neodarwinismo que, segundo o autor, se apropriou de forma indevida das ideias de Darwin e defende que SeresAnimais estão ao mundo para maximizarem suas sobrevivências, geralmente à custa de outros. Situação similar ocorrendo, conforme o autor ao chamado darwinismo social, que de maneira distorcida das proposições de Darwin busca justificar a opressão da sociedade capitalista dos ricos (fortes) e pobres (fracos). Desconsideraram, portanto, os neodarwinistas, a possibilidade de cooperação e empatia entre os Seres-Vivos, ao que o autor rebate com seus estudos junto a macacos, golfinhos e elefantes, os quais demonstram capacidade de cooperar e ajudar ao próximo, com predisposição a cuidar uns dos outros, ajudar-se mutuamente e até salvar a vida de outrem (humanos e não humanos).

Lakatos (1990) descreve que são poucos os casos devidamente estudados por cientistas sobre crianças que foram encontradas vivendo em companhia de animais, sendo o mais famoso o das "meninas-lobo da Índia"6, as quais, quando encontradas, apresentavam características de tais Seres-Animais: "andavam sobre os quatro membros, soltavam grunhidos e tinham apurada visão noturna" (p. 80).

Ainda sobre a relação interespécies entre Crianças e Lobos, em reportagem, Lorenzetto (2018) versa sobre o garoto espanhol Marcos Rodriguez, que encontrado na selva com 19 anos não andava erguido como os humanos, andava descalço, sem roupas, envolto com peles nos períodos frios, quando nevava. Também não falava, uivava como lobos. Na continuidade afirma que Marcos, conhecido como o "Menino-Lobo", não gosta das histórias de Chapeuzinho Vermelho e dos Três Porquinhos, pois nestas os adultos assustam as crianças sem razão.

Uma reportagem, da Folha de S. Paulo, traz a foto de Pisco Del Gaiso ${ }^{7}$ (1992) da mulher indígena do povo Guajá, autodenominado Awá, localizada no estado do Maranhão, segurando o filho dela ao mesmo tempo em que amamenta um cateto, tratando-o também como filho legítimo, visando preservar a fauna ao cuidar e alimentar deste e outros animais órfãos encontrados na floresta.

\section{BEM-VIVER-INTERESPÉCIES}

Mesmo diante de uma área de estudo em emergência em que variadas expressões, conceitos, noções, palavras-chave, descritores são utilizados pela própria novidade e disputas no campo ${ }^{8}$, as explanações e inquietações acima colocadas, nos levam a propor, neste ensaio, o que estamos denominando de Bem-Viver-Interespécies, no sentido de reconhecemos, por certo, a existência dessa pluralidade conceitual (e política), entendendo que nossa própria proposição é, neste momento de nossas pesquisas, mais próxima a uma conjectura do que propriamente a uma proposição teórico-conceitual, e a remetemos para reflexão no ativismo relacionado à causa animal. A ideia é trabalhar de modo propositivo (fazer anúncios como nos ensina Freire (2011) para edificação de inter-relações "Seres-Humanos - Seres-Animais", inspirando-nos no

\footnotetext{
${ }^{6}$ Trata-se de Amala e Kamala, encontradas em Midnapore, Índia, em 1920.

${ }^{7}$ Foto disponível em: < https://www1.folha.uol.com.br/folha/galeria/exposicao/p_expo_cidi_08.shtml > Acesso em: 03 abr. 2019.

${ }^{8}$ Tais como: causa animal, proteção animal, questão animal, abolicionismo animal, direito animal, ética animal, multiespecísmo, antiespecísmo, especísmo, entre outros.
} 
conceito de Bem-Viver (por alguns autores também denominado de "vida boa"). Entendemos neste ensaio o Bem-Viver como uma epistemologia do sul por excelência de povos indígenas latino-americanos (conforme descrevem DUSSEL, 2003; QUIJANO, 2013; ACOSTA, 2016; GONÇALVES JUNIOR; LEMOS; CHECCHI, 2019; MUNDURUKU, 2019). Inspiramo-nos também no conceito de Interculturalidade (em acordo com SANTOS; MENESES, 2009; CANDAU, 2008).

Acerca da "vida boa", Dussel (2003) afirma que "[...] não é principalmente o fim [...] de uma razão instrumental ou estratégica, mas é um modo de vida 'comunitária' (ideal ou real), que deveria ser o cumprimento do reconhecimento ético-originário intersubjetivo do Outro como outro" (p. 27).

Em acordo com Quijano (2013):

\begin{abstract}
"Bem Viver" e "Bom Viver" são os termos mais difundidos no debate do novo movimento da sociedade, sobretudo da população vista como indígena na América Latina, a partir de uma existência social diferente da que nos tem imposto a "Colonialidade" do Poder. "Bem Viver" é, provavelmente, a formulação mais antiga na resistência "indígena" contra a "Colonialidade" do Poder. [...] No quéchua do norte do Peru e no Equador, se diz "Allin Kghaway" (Bem Viver) ou "Allin Kghawana" (Boa Maneira de Viver) e no quéchua do sul e na Bolívia costuma-se dizer "Sumac Kawsay" e se traduz [...] como "Bem Viver". Mas "Sumac" significa bonito, lindo, no norte do Peru e no Equador. Assim, por exemplo, [...] "Sumac Kawsay" se traduziria como "Viver Bonito" (p. 46).
\end{abstract}

Acosta (2016) observa que entre os Aymara, habitantes do norte do Chile e regiões fronteiriças com Peru e Bolívia, se faz presente a expressão Suma Qamaña (boa vida), e entre os Guarani, habitantes de regiões no Brasil, Bolívia, Paraguai e Argentina, a expressão usual é Nhandereko (nosso modo de viver), em todos os casos havendo princípios éticos e estéticos similares no modo de viver a vida.

No Equador, há inclusive registro dos Direitos da Natureza na Constituição, conforme artigo 238:

O sistema econômico é social e solidário; reconhece o ser humano como sujeito e fim; tende a uma relação dinâmica e equilibrada entre sociedade, Estado e mercado, em harmonia com a Natureza; e tem por objetivo garantir a produção e a reprodução das condições materiais e imateriais que possibilitem o Buen Vivir (Constituição do Equador, citada por ACOSTA, 2016, p. 174).

Conforme destacam Gonçalves Junior, Lemos e Checchi (2019) o modo de vida dos povos indígenas pode ser uma resposta para a permanência da vida na Terra, inclusive a humana. Esse modo de vida se contrapõe ao que vem sendo indicado em políticas públicas, e em estudos científicos que as sustentam, como desenvolvimento humano, desenvolvimento sustentável, desenvolvimento econômico, entre outros que têm sido associados à ideia de "desenvolvimento", associado ao entendimento do SerHumano não como um dos Seres-Vivos, mas como superior aos demais Seres-Vivos.

Neste sentido, o indígena Daniel Munduruku (2019) afirma:

[...] as gentes indígenas sabem que fazem parte de um universo que os tornam irmãos de todos os viventes. Essa compreensão é a mola mestra que compõe a filosofia e a teologia indígenas. É ela que questiona o mundo materialista ocidental, o qual confunde ser e ter, possuir e pertencer, cuidar e destruir... Enquanto as pessoas continuam pensando como seres individuais, o mundo estará em perigo, pois pensar dessa maneira é considerar-se superior a todas 
as coisas e procurar controlar, dominar, comprar, consumir e destruir (p. 2122).

Munduruku (2019) acrescenta que quando pensa na diversidade, na diferença étnico-racial, social e na atualmente denominada sustentabilidade, palavra nova para a antiga necessidade do ser humano ocupar o seu lugar no mundo, percebe a epistemologia dos povos indígenas, na qual:

[...] tudo está em harmonia com tudo; tudo está em tudo e cada um é responsável por essa harmonia. É uma concepção que não excluir nada e não dá importância a um único elemento, pois todos são passageiros de uma mesma realidade, sendo, portanto, iguais. No entanto, não se pode pensar que essa igualdade signifique uniformidade. Todos esses elementos são diferentes entre si, têm personalidade própria, identidade própria (p. 33).

Tal diversidade é fundamental para compreender a interculturalidade, observando situações de diferença e desigualdade de gênero, de classe social, de raça, de espécie presentes na sociedade e sua complexidade. Como nos alerta Candau (2008) é imprescindível assumir agenda política de transformação, de lutas sociais, privilegiando "a transformação das relações sociais, culturais e institucionais" (p. 51), bem como, afirmamos: interespécie, com base no que já vimos argumentando na seção inicial deste ensaio, em relação à cultura e Seres-Animais.

Santos e Meneses (2009) alertam que a interculturalidade pressupõe “[...] o reconhecimento recíproco e a disponibilidade para enriquecimento mútuo entre várias culturas que partilham de um dado espaço cultural" (p. 9). Interculturalidade esta que é construída no processo mesmo de reconhecer a reciprocidade e a riqueza que essa experiência pode fomentar, para além de mera aceitação ou tolerância de uma cultura por outra (acrescentamos aqui: de uma espécie por outra), que se coloca, hierarquizada, como dominante.

Junto a isto, como nos recorda Araújo-Olivera (2014, p.100) a ideologia eurocêntrica "[...] fundada num jogo de divisão binária hierarquizada" faz com que a cultura do centro (branca, heterossexualmente patriarcal, judaico-cristã) comporte-se e sustente a cisão entre o divino, o Ser-Humano e a natureza. Nas palavras da autora (p.101):

\footnotetext{
Nessa hierarquia coloca-se o homem acima de todas as outras criaturas da Terra, conferindo-lhe o direito de intervir e controlar o curso dos acontecimentos na Terra. Considerando o proprietário da natureza, exerce domínio por meio da ciência e da técnica, com severas consequências para o equilíbrio biológico e desenvolvimento da vida. [...] As relações hierárquicas entre tipos de saberes, uns pretendidamente universais perante outros tidos como locais, bem como a desqualificação das formas de saber, a produção do conhecimento e acúmulo de resultados sobre se educar, cuidar da saúde, próprios dos povos originários e de descendentes das populações africanas escravizadas, fazem parte destas compreensões, e permanecem como herança colonial.
}

Assim, com base nas reflexões apresentadas anteriormente, anunciamos, mesmo que de forma inicial, neste ensaio a possibilidade de se pensar a interconexão conceitual entre Bem-Viver e os Estudos Críticos Animais, no conceito de o Bem-ViverInterespécies. Entendemos que nas culturas dos povos originários, que são as que fundamentam o conceito de Bem-Viver, a expressão "interespécies" pode soar, a priori, destoante, uma vez que tal expressão pressupõe uma divisão entre espécies Humana e 
Não Humana, e não é isso que vemos, por exemplo, na afirmação de Munduruku (2019) anteriormente indicada, que nos explana que para as gentes indígenas, os seres viventes são irmãos. Não haveria, portanto, espécies como as que conhecemos biologicamente, em nossa cultura acadêmica. O Bem-Viver-Interespécies primeiramente denuncia tal divisão como entre "ser" e "não ser", e, em segundo lugar, procura superar a relação hierárquica entre espécies buscando no Bem-Viver a base propositiva para essa superação, trazendo para debate a possibilidade da síntese cultural pelas culturas fundantes do Bem-Viver do que temos como cultura de exploração dos Seres-Animais. No entanto, ainda não supera a própria divisão entre espécies, uma vez incorpora essa denominação. A contradição, esperamos, seja futuramente superada. Mas neste momento, nos parece que a tensão que tal proposição apresenta pode vir a abrir caminhos para a convivência ética entre espécies.

Este Bem-Viver iria para além da mera aceitação ou tolerância de uma espécie por outra, que se coloca como dominante, a construção de novas relações é complexa e envolve conflitos, contudo, pode também anunciar uma ética de solidariedade, empatia e alteridade, de Seres integrados e interdependentes que com respectivas diversidades precisam uns dos outros para existência, co-existência e bem-viver na Terra.

Por fim, pelo contexto de destruição e extinção de espécies vegetais e animais que temos assistido no planeta, cada vez mais indicando a finitude deste e da vida, compreendemos que se faz necessária esta proposição do Bem-Viver-Interespécies "SerHumano - Ser-Animal", entendidos como extensões uns dos outros na teia da vida, para que prossiga a possibilidade de futuro dos Seres-Vivos ou Viventes no planeta, em nossa casa, como nos ensina Mundurunku (2019). 


\section{REFERÊNCIAS}

ACOSTA, A. O bem viver: uma oportunidade para imaginar outros mundos. São Paulo: Autonomia Literária, 2016.

ARAÚJO-OLIVERA, S. S. Exterioridade: o outro como critério. In: OLIVEIRA, M. W.; SOUSA, F. R. (Org.). Processos educativos em práticas sociais: pesquisas em educação. São Carlos: EdUFSCar, 2014. p. 47-112.

ÁVILA-GAITÁN, I. D. El Instituto Latinoamericano de Estudios Críticos Animales como proyecto decolonial. Tabula Rasa, Bogotá - Colombia, n. 27, p. 339-351, jul.-dic. 2017.

BEST, S. The rise of critical animal studies: putting theory into action and animal liberation into higher education. Journal for Critical Animal Studies, v. 7, n.1, p. 9-52, 2009.

BRÜGGER, P. Educação ou adestramento ambiental? 2. ed. Santa Catarina: Letras Contemporâneas, 1999.

CAILLOIS, R. Os jogos e os homens: a máscara e a vertigem. Petrópolis: Vozes, 2017.

CANDAU, V. M. Direitos humanos, educação e interculturalidade: as tensões entre igualdade e diferença. Revista Brasileira de Educação, v. 13, n. 37, p. 45-56, 2008.

CASTEllanO, M.; SORRENTINO, M. A inserção de estudos críticos animais em instituições de educação superior. Atos de Pesquisa em Educação, Blumenau, v. 10, n. 2, p. 654-680, 2015.

DE WAAL, F. A era da empatia: lições da natureza para uma sociedade mais gentil. São Paulo: Companhia das Letras, 2010.

DEL GAISO, P. Índia Guajá amamenta filhote de porco do mato. Folha de S. Paulo, 16 dez. 1992.

DUSSEL, E. Alguns princípios para um ética ecológica material de libertação (relações entre a vida na terra e a humanidade). In: PIXLEY, J. (Coord.). Por um mundo diferente: alternativas para o mercado global. Petrópolis: Vozes, 2003. p. 23-35.

DUSSEL, E. Cultura imperial, cultura ilustrada e libertação da cultura popular. In: DUSSEL, E. Oito ensaios sobre cultura latino-americana e libertação. São Paulo: Paulinas, 1997. p. 121-152.

DUSSEL, E. Filosofia da libertação na América Latina. São Paulo: Loyola; Piracicaba: Unimep, 1977.

FELIPE, S. T. Por uma questão de princípios: alcances e limites da ética de Peter Singer em defesa dos animais. Florianópolis: Fundação Boiteux, 2003.

FORTE, D. L. Representaciones animales y procesos de borramiento en el conflicto Cresta Roja. Logos, La Serena, v. 27, n. 1, p. 105-122, jul. 2017.

FREIRE, P. Pedagogia do oprimido. 50. ed. Rio de Janeiro: Paz e Terra, 2011.

GONÇALVES JUNIOR, L.; LEMOS, F. R. M.; CHECCHI, C. M. S. Do conformismo do lazer à radicalidade do ócio: esperançando o bem viver. In: SILVA, J. V. P.; SILVA, D. S. (Org.). Lazer, vida com qualidade e direitos sociais. Curitiba: InterSaberes, 2019. (no prelo).

HARAWAY, D. When species meet. Minneapolis, University of Minnesota Press, 2008.

HUIZINGA, J. Homo ludens: o jogo como elemento da cultura. 4. ed. São Paulo: Perspectiva, 2000.

KIRKSEY, S. E.; HELMREICH, S. The emergence of multispecies ethnography. Cultural Anthropology, v. 25, n. 4, p. 545-576, 2010.

LAKATOS, E. Sociologia geral. 6. ed. São Paulo: Atlas, 1990.

LÉVINAS, E. Entre nós: ensaios sobre a alteridade. 2. ed. Petrópolis: Vozes, 2005. 
LORENZETTO, M. S. Verdadeiro menino lobo vive mal entre humanos. Campo Grande News, 28 mar. 2018. Disponível em: < https://www.campograndenews.com.br/colunistas/em-pauta/verdadeiro-meninolobo-vive-mal-entre-humanos >. Acesso em: 26 mar. 2019.

MACIEL, M. E. (Org.). Pensar e escrever o animal: ensaios de zoopoética e biopolítica. Florianópolis: Editora da UFSC, 2011.

MALDONADO-TORRES, N. A topologia do ser e a geopolítica do conhecimento. Modernidade, império e colonialidade. In: SANTOS, B. S. Epistemologias do sul. São Paulo: Cortez, 2010. p. 396-443.

MATURANA, H.; DÁVILA, X. El arbol del vivir. Santiago: Escuela Matriztica/ MVP Editores, 2015.

MUNDURUKU, D. Das coisas que aprendi: ensaios sobre o bem-viver. 2. ed. Lorena: DM Projetos Especiais, 2019.

NACONECY, C. Ética e animais: um guia de argumentação filosófica. Porto Alegre: EDIPUCRS, 2014.

OGDEN, L.; HALL, B.; TANITA, K. Animals, plants, people, and things: a review of multispecies ethnography. Environment and Society: Advances in Research, n. 4, p. 5-24, 2013.

OLIVEIRA, M. W.; SILVA, P. B. G.; GONÇALVES JUNIOR, L.; GARCIA-MONTRONE, A. V.; JOLY, I. Z. Processos educativos em práticas sociais: reflexões teóricas e metodológicas sobre pesquisa educacional em espaços sociais. In: OLIVEIRA, M. W.; SOUSA, F. R. (Org.). Processos educativos em práticas sociais: pesquisas em educação. São Carlos: EdUFSCar, 2014. p. 29-46.

OSTOS, N. S. C. A luta em defesa dos animais no Brasil: uma perspectiva histórica. Ciência e Cultura, São Paulo, v. 69, n. 2, p. 54-57, abr. 2017.

PODBERSCEK, A.; PAUL, E.; SERPELL, J. Companion animals and us: exploring the relationships between people and pets. Cambridge: Cambridge University Press, 2005.

QUIJANO, A. "Bem viver": entre o "desenvolvimento" e a "des/colonialidade" do poder. Revista da Faculdade de Direito da UFG, v. 37, n. 1, p. 46-57, 2013.

SANTOS, B. S. A gramática do tempo: para uma nova cultura política. 3. ed. São Paulo: Cortez, 2010.

SANTOS, B. S.; MENESES, M. P. Introdução. In: SANTOS, B. S.; MENESES, M. P. (Org.). Epistemologias do sul. Coimbra: Edições Almedina, 2009. p. 9-19.

SINGER, P. Libertação animal. São Paulo: Martins Fontes, 2010.

SÜSSEKIND, F. O rastro da onça: relações entre humanos e animais no Pantanal. Rio de Janeiro: 7Letras, 2014.

VANDER-VELDEN, F. F. Os primeiros cachorros: encontros interétnicos e multiespecíficos no sudoeste da Amazônia. Revista Brasileira de Ciências Sociais, v. 33, n. 97, p. 1-28, 2018.

VARELA, F. J.; THOMPSON, E.; ROSCH, E. De cuerpo presente: las ciencias cognitivas y la experiencia humana. Barcelona: Gedisa, 1997.

VIDELA, M. D. ¿Que és uma mascota? Objetivos y miembros de la familia. Ajayu, La Paz, v. 15, n. 1, p. 53-69, mar. 2017.

WILSON, E. O. A conquista social da terra. São Paulo: Companhia das Letras, 2013.

Recebido em: 26 mar. 2019.

Aprovado em: 27 abr. 2019. 